\title{
Predicting potential impacts of climate change on the geographical distribution of mountainous selaginellas in Java, Indonesia
}

\author{
AHMAD DWI SETYAWAN ${ }^{1,2, \bullet}$, JATNA SUPRIATNA ${ }^{3}$, NISYAWATI ${ }^{3}$, ILYAS NURSAMSI $^{4}$, SUTARNO $^{2}$, \\ SUGIYARTO $^{2}$, SUNARTO ${ }^{1}$, PRAKASH PRADAN ${ }^{5}$, SUGENG BUDIHARTA ${ }^{6}$, ARI PITOYO ${ }^{2}$, \\ SAPTA SUHARDONO ${ }^{1}$, PRABANG SETYONO ${ }^{1}$, MUHAMMAD INDRAWAN ${ }^{1}$ \\ ${ }^{1}$ Department of Environmental Science, Faculty of Mathematics and Natural Sciences, Universitas Sebelas Maret. J1. Jend. Urip Sumoharjo No. 179, \\ Surakarta 57 128, Central Java, Indonesia. \\ ${ }^{2}$ Department of Biology, Faculty of Mathematics and Natural Sciences, Universitas Sebelas Maret. J1. Ir. Sutami 36A Surakarta 57 126, Central Java, \\ Indonesia \\ ${ }^{3}$ Department of Biology, Faculty of Mathematics and Natural Sciences, Universitas Indonesia. Jl. Lingkar Akademik, Depok 16424, West Java, Indonesia \\ ${ }^{4}$ Bird Conservation Society (BICONS). Bandung 40184, West Java, Indonesia \\ ${ }^{3}$ West Bengal Biodiversity Board, Department of Environment, Government of West Bengal, Salt Lake, Sector-III, FD415A, Poura Bhawan, 4th Floor, \\ Kolkata, West Bengal, India \\ ${ }^{6}$ Purwodadi Botanic Garden, Indonesian Institute of Sciences. J1. Raya Surabaya-Malang Km. 65, Purwodadi, Pasuruan 67163, East Java, Indonesia
}

Manuscript received: 29 April 2020. Revision accepted: 27 September 2020.

\begin{abstract}
Setyawan AD, Supriatna J, Nisyawati, Nursamsi I, Sutarno, Sugiyarto, Sunarto, Pradan P, Budiharta S, Pitoyo A, Suhardono S, Setyono P, Indrawan M. 2020. Predicting potential impacts of climate change on the geographical distribution of mountainous selaginellas in Java, Indonesia. Biodiversitas 21: 4866-4877. Selaginella is a genus of non-flowering plant that requires water as a medium for fertilization, as such, it prefers mountainous areas with high level of humidity. Such unique ecosystem of Selaginella is available in some parts of Java Island, Indonesia, especially in highland areas with altitude of more than 1,000 meters above sea level. However, most mountainous areas in Java are likely to be affected by climate change due to global warming, threatening the habitat and sustainability of Selaginella. This study aimed to investigate the impacts of climate change on the geographical distribution of Selaginella opaca Warb. and Selaginella remotifolia Spring. In doing so, we predicted the suitable habitats of both species using Species Distribution Model (SDM) tool of MaxEnt under present climate conditions and future conditions under four climate change scenarios. Species occurrence data were obtained from fieldworks conducted in 2007-2014 across Java Island (283 points: 144 and 139 points for S. opaca and S. remotifolia, respectively) and combined with secondary data from Global Biodiversity Information Facility (GBIF) (52 points: 35 and 17 points for S. opaca and S. remotifolia, respectively), and this dataset was used to model present geographical distribution using environmental and bioclimatic variables. Then, future distribution was predicted under four climate change scenarios: i.e. RCP (Representative Carbon Pathways) 2.6, RCP 4.5, RCP 6.0, and RCP 8.5 in three different time periods (2030, 2050, and 2080). The results of the models showed that the extent of suitable habitats of $S$. opaca and S. remotifolia will be reduced between $1.8-11.4 \%$ due to changes in climatic condition, and in the areas with high level of habitat suitability, including Mount Sumbing, Mount Sindoro and Mount Dieng (Dieng Plateau), the reduction can reach up to $60 \%$. This study adds another context of evidence to understand the potential impacts of climate change on biodiversity, especially on climate-sensitive species, such as Selaginella, in climate-risk regions like mountainous areas of Java Island.
\end{abstract}

Keywords: Java, mountainous areas, climate change, Selaginella ornata, S. remotifolia

\section{INTRODUCTION}

Selaginella Pal. is a single genus of ferns belong to Selaginellaceae family that lives in moist areas and is often found in highlands (Wijayanto 2014). Some species of Selaginella have a wide distribution and tend to be invasive, but the others are endemics, or even endangered according to IUCN criteria (Setyawan et al. 2015). Studies on the diversity of this genus recorded a global distribution across several continents. Within the scope Asian continent, Selaginella has been found in India (e.g. Singh et al. 2014), Taiwan (e.g. Ebihara et al. 2012), Philippines (e.g. Zamora 2012), China (e.g. Banks 2008), Thailand (e.g. Rupa and Bhavani 2014), Japan (e.g. Ebihara et al. 2012), and Papua New Guinea (e.g. Jorim et al. 2012). In Indonesia alone, from 1998 until 2014, as many 39 species of Selaginella had been found with 22 species were found in Java Island (Wijayanto 2014).

Java Island, like other areas in equatorial zone, has two seasons, i.e. dry season (during May-September) and wet season (during October-April). Java Island has a wide range of precipitation which is divided into three categories of area. The western region of Java (Banten and West Java Province) and central region of Java (Central Java and Special Region of Yogyakarta) have the same average rainfall at about $2,000 \mathrm{~mm}$ per year, but in some mountainous areas in western Java the precipitation could reach 3,000 to 5,000 $\mathrm{mm}$ per year. On the other hand, the eastern area of Java has a lower precipitation with about $1900 \mathrm{~mm}$ per year (Qian et al. 2010). Likewise, average temperature in Java has a broad range according to altitude feature. The coastal areas have an average temperature 
ranges between $22{ }^{\circ} \mathrm{C}$ to $32{ }^{\circ} \mathrm{C}$, while in higher areas with an altitude of between 400-1350 m a.s.l (above sea level) the average temperature ranges between $18{ }^{\circ} \mathrm{C}-29{ }^{\circ} \mathrm{C}$. Higher altitude generally means a lower range of temperature, in this case, the lowest temperature in Java island can reach minus $4^{\circ} \mathrm{C}$ which was recorded in Ranu Pani area in the slope of Mount Semeru (Hariyati et al. 2013).

The broad range of temperature and precipitation in Java makes suitable for Selaginella to have a wide horizontal and vertical geographical distribution. Altitudinally, Selaginella grows in lowlands, highlands and the ecotone (the transitional zones between the two areas), each with its own preference (Setyawan 2008). For example, the vast extent of mountainous areas in Java with varying climatic features supports the growth of Selaginella opaca Warb. and Selaginella remotifolia Spring., two of the most dominant and prominent species of mountainous Selaginella in Java. Traditionally, S. opaca and $S$. remotifolia are used as medicinal plants to treat wounds, menstruation disorders, and even as enhance body fitness (Setyawan 2009).

Due to its potential uses as mentioned earlier, there is an increasing interest to study Selaginella. However, current trend on the research and conservation of Selaginella has been more focused on the studies of the aspect of taxonomy (e.g. Christian 2013; Weststrand and Korall 2016), morphology (e.g. Schulz et al. 2010, 2013; Singh 2014), utilization (e.g. Setyawan 2009), molecular biology (e.g. Korall and Kenrick 2004; Li et al. 2007) and ethnobotany (e.g. Setyawan and Darusman 2008; Setyawan 2009). Meanwhile, studies on the habitat ecology and geographical distribution of Selaginella remain limited. Since most Selaginella in Indonesia naturally grows in humid and cool areas, which are currently threatened by natural degradation and global warming, there is an urgent need for conservation efforts to ensure the sustainable use of this biological resource (Setyawan 2011). The detailed knowledge of Selaginella's habitat preferences and distribution is a prime priority for any decision making and action plans in the wildlife management and conservation, in order to guarantee long term survival of this genus.

Since the early $20^{\text {th }}$ century, scientific community has recognized the impacts of climate changes, induced by greenhouse gases (GHG), on biodiversity. Climate change has been proved as a perverse outcome of human activities (Karl and Trenberth 2003; IPCC 2007). Climate, since long time ago, has been identified as a primary control of the geographic distribution of plants (e.g. Forman 1964; Box 1981). Therefore, the distribution of a plant should be expected to exhibit as its response to climate change. In this context, the current and potential future distribution of species in regard to global climate change has been widely investigated (e.g. Thuiller 2007; Kudela 2009). The methodological foundations for such theoretical concepts have been developed in the framework of species distribution modeling (SDM), also called niche modeling or bioclimatic envelopes modeling (Elith and Leathwick 2009).
Species distribution models (SDMs) are numerical tools that combine observation data on species occurrence or abundance with environmental estimates. They are used to gain ecological and evolutionary insights and to predict distributions across landscapes, sometimes requiring extrapolation in space and time (Elith and Leathwick 2009). Species distribution models are useful tools for, among other things, informing the conservation management of wildlife and their habitats under a rapidly changing climate (Porfirio et al. 2014), modeling the potential impacts of climate change on extinction risk (Garavito 2015), and predicting spatial patterns of species biodiversity (Dubuis et al. 2013).

Developing species distribution models can be performed using a variety of algorithms, including combinatorial optimization (e.g. GARP_Fitzpatrick et al. 2007), statistical models (e.g. GAMs_-Jensen et al. 2008), heuristic models (e.g. BIOCLIM-Beaumont and Hughes 2002), and machine learning (e.g. ANN_ Ostendorf et al. 2001, Berry et al. 2002, Harrison et al. 2013; MaxEntPhillips et al. 2006) (Sinclair et al. 2010). Maximum Entropy (MaxEnt) modeling has a great potential for identifying distributions and habitat selection of wildlife given its reliance on presence-only data (Baldwin 2009). MaxEnt is a general-purpose machine learning method with a simple and precise mathematical formulation, and it has a number of aspects that make it well-suited for species distribution modeling (Phillips et al. 2013). The approach presented by MaxEnt appears to be quite promising in predicting suitable habitat for threatened and endangered species with small sample records and can be an effective tool for biodiversity conservation planning, monitoring, and management (Kumar and Stohlgren 2009). MaxEnt has the ability to utilize different climatic scenarios to estimate the extent of occurrence of species (Beaumont et al. 2007), allowing the evaluation of the impact of climate changes on geographical distribution of species (e.g. Rondini et al. 2006; Botkin et al. 2007; Randin et al. 2008; Engler and Guisan 2009; Garavito 2015).

The purposes of this study are to model the geographical distribution of Selaginella opaca Warb. and Selaginella remotifolia Spring. under present climate conditions, and model its future distribution under the influence of climate change. By using MaxEnt software, we built the models based on localities data and bioclimatic features, in combination with climate change scenarios across predetermined time intervals until 2080. We assume that as a response to climate change, there will be a change in geographical distribution of S. opaca and S. remotifolia.

\section{MATERIALS AND METHODS}

\section{Study area}

This study covered Java Island (Indonesia), one of the main habitats of the Selaginella. Java Island has been known as one of the 25 identified biodiversity hotspots by Myers et al. (2000) and it is closely located with the four biologically richest hotspots, such as Indo-Burma, Peninsular Malaysia, Wallacea, and The Philippines. 
Tropical lowland rain forest in these regions, the richest ecosystems in the world, is being cleared for commercial uses, settlement expansion, and logging. Such problems are massively occurring in Java Island, thus responsible for the increasing level of greenhouse gasses which is expected to negatively affect the condition of Selaginella's habitat.

Java Island has approximately $133,930 \mathrm{~km}^{2}$ of land area and altitudinal ranges from $0-3,676 \mathrm{~m}$ a.s.l. All of the locality points were collected in the mountainous area of Java. Records points were selected carefully to represent the geographical distribution of both $S$. opaca and $S$. remotifolia in Java Island (Figure 1).

\section{Procedures}

\section{Locality data}

Geo-referenced occurrence records of Selaginella opaca Warb. and Selaginella remotifolia Spring. across Java Island were obtained from field survey data collected between 2007 and 2014 with a high confidence level of taxonomic identification. A total of 283 species occurrence points (consisted of 144 points of S. opaca and 139 points of $S$. remotifolia) were collected in highland areas of Java Island using a GPS (Garmin eTrex Series). The accuracy of the GPS is normally between $0.01 \mathrm{~km}$ to $0.05 \mathrm{~km}$. According to a study conducted by Montgomery et al. (2011) this level of telemetry error, which is much smaller than the resolution of predictors, is expected to have a little effect on the accuracy of predicted models. Thus, an errorcorrection for these data was not performed. In addition, several geo-referenced occurrence records of both species (35 points of $S$. opaca and 17 points of S. remotifolia) were acquired from the Global Biodiversity Information Facility (GBIF) website (http://www.gbif.org). So, 335 points used in this study, include 151 points of $S$. opaca and 156 points of $S$. remotifolia.

Sampling bias has been argued to have a strong influence on SDM prediction ability (Fourcade et al. 2013; Fourcade et al. 2014). Therefore, we initially accounted for spatial sampling bias by performing a spatial filtering (Leitao et al. 2011; Syfert et al. 2013; Boria et al. 2014; Yoan et al. 2014). Automatically, MaxEnt will perform spatial filtering by removing duplicate points that fall into a single environmental cell (Merrow et al. 2013). To enhance the spatial filtering, we reduced the locality points by only one point per $2 \mathrm{~km}$ radius within each point. The $2 \mathrm{~km}$ radius was chosen based on the modification of a $10-\mathrm{km}$ radius used by Pearson et al. (2007); Anderson and Raza (2010) in their study which was conducted in mountainous areas with high spatial heterogeneity. Considering the level of spatial heterogeneity of climate variability over Java Island (Qian et al. 2010), we decided to reduce the radius used in those studies from $10 \mathrm{~km}$ to $3 \mathrm{~km}$. Moreover, this distance was chosen to reduce the geographic biases associated with collection data, rather than to approximate the species' dispersal capabilities. Geographic Distance Matrix Generator ver 1.2.3 was used to calculate the geographic distance between each pair of occurrence records (Erst 2012).

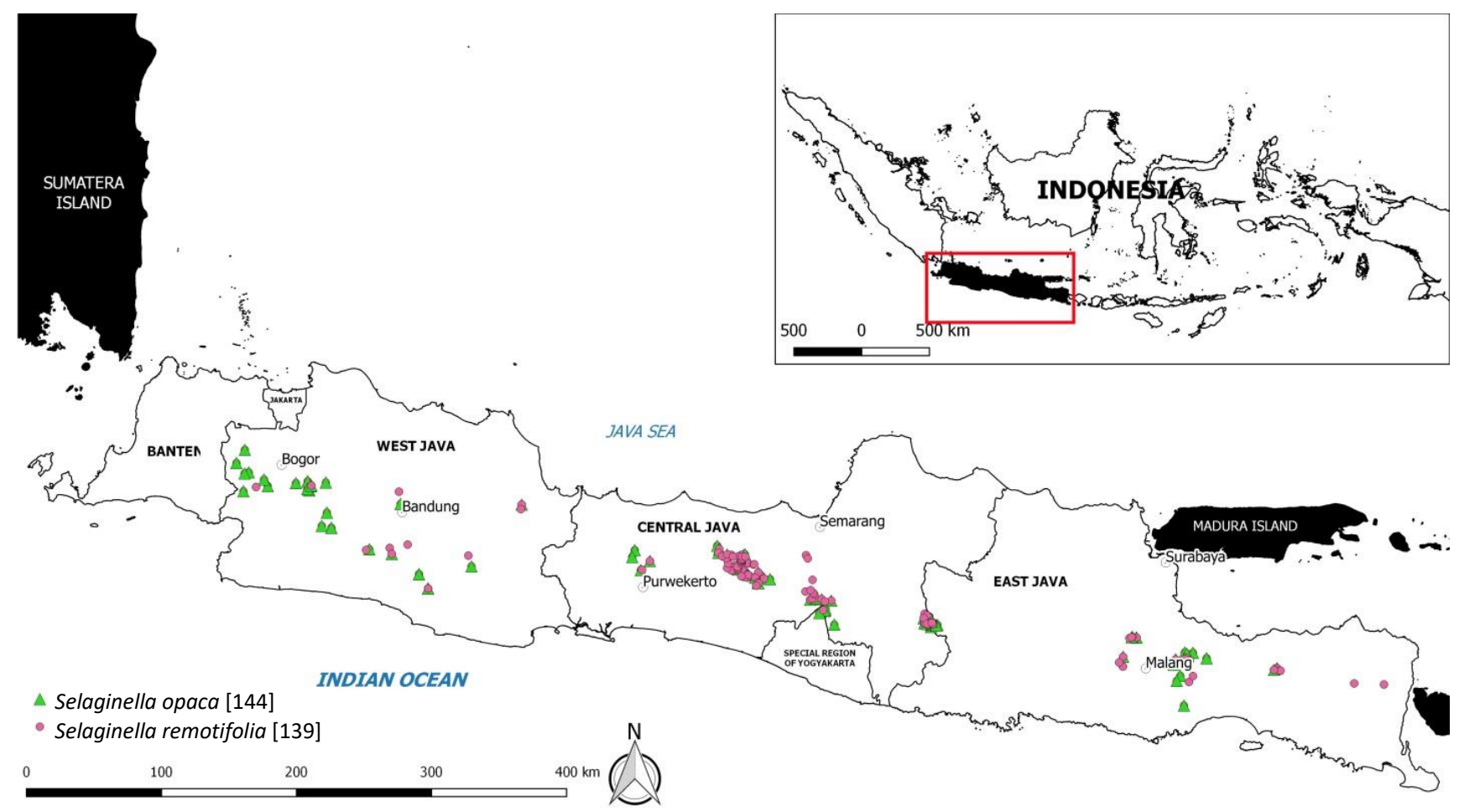

Figure 1. Localities data of Selaginella opaca and S. remotifolia across Java Island, Indonesia 


\section{Predictor variables}

Modeling the $S$. opaca and $S$. remotifolia habitat suitability and potential distribution across Java Island under current and future climate conditions were conducted using a set of environmental and bioclimatological variables. In total, we used 22 datasets, consisted of geological features of Java Island, soil type, elevation data, and 19 bioclimatic data layers (11 temperature and 8 precipitation variables). Bioclimatic data were extracted from WorldClim Bioclimatic datasets (http://www.worldclim.org). This website provides 19 bioclimatic variables that are interpolated and modeled from observations and averaged over the period 1970 until 2000 at $1 \mathrm{~km}^{2}$ spatial resolution. Elevation data were also extracted from the WorldClim database with the same spatial resolution. Geological features and soil types of Java Island were collected from freely available Indonesian Geospatial Information Agency's (Indonesian: Badan Informasi Geospatial, abbreviation: BIG) website. Those data were not ready to use yet, and then, were processed in advance by using geographic information systems method. The process was image cutting, resampling of data in a geographic coordinate system of WGS48 at a resolution of $1 \mathrm{~km}^{2}$ (0.008333 decimal degree), and file format converting into ASCII format. All of these processes were performed using QuantumGIS software ver 2.8.10. Since future prediction of land use/land cover changes, human disturbances, and changes in biotic interaction is limited, we did not take these factors into account.

To predict the effect of climate change on the potential distribution of the two mountainous Selaginella species under several climate change trajectories, future climate datasets freely provided by CGIAR Research Program on Climate Change, Agriculture, and Food Security (www.ccafs-climate.org) were used. The future climate datasets were downscaled to a $1-\mathrm{km}^{2}$ spatial resolution from its original resolution at scale 100 to $200 \mathrm{~km}^{2}$ using the delta method. The delta method interpolates the General Circulation model generally used in climate modeling using a thin plate spline spatial interpolation method to achieve the 30 arc seconds resolution $\left(1 \mathrm{~km}^{2}\right)$ (Ramirez and Jarvis 2008). We selected four RCP (Representative Carbon Pathways), which represents the future greenhouse gas (GHG) trajectories, namely RCP 2.6, RCP 4.5, RCP 6.0, and RCP 8.5 in three different time periods (2030, 2050, and 2080). In this study, we selected the HadGEM2-CC (Hadley Global Environment Model-2 Carbon Cycle) Global Circulation Model, which was developed by the Hadley Center, United Kingdom (Collins et al. 2011). HadGEM2-CC model has been used to perform all the CMIP5 (Coupled Model Inter-comparison Project Phase 5) centennial experiments including ensembles of simulations of the RCPs (Shrestha et al. 2014). RCP 2.6 assumes that global GHG will increase slowly to reach its peak at $3.1 \mathrm{~W} / \mathrm{m}^{2}$ between $2010-2020$, with emissions declining substantially thereafter at 2.6 $\mathrm{W} / \mathrm{m}^{2}$ by the year 2100 (Van Vuuren et al. 2007; Moss et al. 2009). Emissions in RCP 4.5 is assumed to be stabilized at $4.5 \mathrm{~W} / \mathrm{m}^{2}$ by the year 2100 due to the employment of a range of technology and strategies to reduce GHG emissions (Clarke et al. 2007). Likewise, the emissions in RCP 6.0 is projected to reach its peak around 2080 and stabilizes by the year 2100 at $6.0 \mathrm{~W} / \mathrm{m}^{2}$. In RCP 8.5 emissions continue to rise throughout the $21^{\text {st }}$ century, reaching around $8.5 \mathrm{~W} / \mathrm{m}^{2}$ as the highest value (Riahi et al. 2011).

The Global Climate Models have been widely used to assess the climate change impact at local to global scales and used as basic information to construct climate change scenarios. However, these models exhibit systematic error (biases) due to the limited spatial resolution, numerical schemes, simplified physics, and thermodynamic processes, or incomplete knowledge of climate system processes (Ramirez-Villegas et al. 2013). Thus, we performed a bias-correction procedure to produce climate projections that fit better for modeling. The Change Factor (CF) and Quantile Mapping (QM) methods were selected in this bias-correction procedure. In the Change Factor (CF) approach, the raw GCM outputs current values are subtracted from the future simulated values, resulting in "climate anomalies" which are then added to the presentday observational dataset (Tabor and Williams 2010). The Quantile Mapping (QM) method was selected to complement the CF method, since the CF method works well for only more non-stochastic variables (i.e. temperature). Thus, a more sophisticated approach for biascorrecting stochastic variables (e.g. precipitation and solar radiation) was needed.

\section{Modeling}

Predictive maps of occurrence under current and future climate conditions were modeled by using MaxEnt software ver. 3.3.3a (Computer Science DepartmentPrinceton University 2004) on the basis of occurrence data and environmental variables (Philips and Dudik 2008; Summers et al. 2012). MaxEnt software was selected since it has been proved suitable to be used with presence-only (PO) data, and provides robust and reliable results (Warren and Seifert 2011). Since 2005, more than 1000 published distribution modeling has been conducted using MaxEnt software (Merow et al. 2013; Fourcade et al. 2014). The popular utilization of MaxEnt is due to higher predictive accuracy than any other method (Elith et al. 2006; Summers et al. 2012). MaxEnt also performs well to estimate the effect of climate change on the potential shifting range of species (Kou et al. 2011; Johnston et al. 2012; Duan et al. 2016).

To minimize the impact of multi-collinearity and overfitting, we calculated pairwise correlation of the predictor variables using $\mathrm{R}$ program ver. 3.4.1 and then removed highly correlated variables $\left(r^{2} \leq 0.80\right)$ (Baldwin 2009; Merow et al. 2013). Out of nineteen variables, nine bioclimatic variables (bio_1, bio_2, bio_3, bio_4, bio_12, bio_13, bio_15, bio_18, and bio_19) and three environmental variables (altitude, geological feature, and soil type) were then used to model the potential distribution of both species under current and future climate condition. Despite the fact that MaxEnt has been shown to give robust 
and reliable results by just using default settings (Phillips et al. 2008), we modify several parameter values to adjust the calculation with our present data and predictor variables. The adjusted parameter values were: five replicated runs (the averaged value is the one used as the result) with "cross validate" as the replicated run type, maximum iterations $=5,000$, and convergence threshold $=10,000$. We also created background points data to be included as a bias file to represent sampling effort to reduce sampling bias (Fourcade et al. 2014). Bias file, ideally, represents the actual sampling effort across the study area or could be estimated by the aggregation of occurrences from closely related species (Phillips et al. 2009). Nevertheless, in most real modeling situations, this information is limited. In consequence, following Elith et al. (2010), authors produced a Gaussian kernel density map of the occurrence locations, rescaled from 1 to 20 to be derived as bias file.

\section{Data analysis}

The main output of MaxEnt program is continuous data showing the potential suitable habitat distribution which linearly scaled between 0 (lowest) to 1 (highest) probability (Philips and Dudik 2008). Furthermore, MaxEnt created calculation of the bioclimatic relative contribution to the model and how these variables affect the MaxEnt prediction. Alternate estimation of variable importance was also collected by running the jackknife test. The results of jackknife test show which variable has the most useful information by itself and which variable appears to have the most information that is not present in the other variables.

MaxEnt will calculate an area under the receiver operating characteristic (ROC) curve (AUC) to evaluate model performance. AUC values can range between 0.5 and 1.0, with 0.5 indicating that the model is no better than random prediction; values below 0.7 are low, values between 0.7 and 0.8 are good, and values $>0.9$ indicate high discrimination or it means that the model is far better than random prediction. Even though the AUC was written as the established method for assessing the fitness of the model in some papers (e.g. Townsend Peterson et al. 2007; Rodder et al. 2010; Donald et al. 2012; and Setiadi 2012), unfortunately, it is also proved wrong by Lobo J.M et al. (2008); Bahn and McGill (2012); and Aguirre-Gutiérrez et al. (2013). These studies also demonstrated that AUC does not provide useful information for assessing SDM performance. Therefore, in this study, the additional evaluation of the model was conducted using True Skill Statistic (TSS) as it has been proved theoretically and empirically better than AUC and also better than Kappa Statistic in measuring the performance of species distribution models (Allouche et al. 2006).

We imported the ASCII file containing the probability of habitat suitability into QuantumGIS software ver. 2.18.10 and reclassified it into three classes: low suitability (25-50\% probability of occurrence), medium suitability, (50-75\% probability of occurrence), and high suitability (>75\% probability of occurrence). The reclassification allowed us to compare the change in every class over time and space. Another analysis was conducted to observe the potential change of altitudinal distribution of S. opaca and
S. remotifolia by compared the mean values of the predicted areas under current and future climate scenarios condition using independent sample T-test. We then compared the total area of predicted habitat under current and projected future climate conditions by counting the number of "presence" grid cells and multiplied it by their spatial resolution.

\section{RESULTS AND DISCUSSION}

\section{Identifying important environmental variables}

Twelve predictor variables (environmental and bioclimatic) were utilized to build the ecological niche model of $S$. opaca and $S$. remotifolia. It is important to note that when a single run of MaxEnt software involves two different species in the same genus, MaxEnt, in its settings option, is able to calculate and give separate results for each species. Therefore, the important variables that contribute to build the model for each species can be compiled and explained separately. The four most important variables that contributed a combined total of $83.8 \%$ to the model were altitude, annual mean temperature (bio_1), geology feature, and mean diurnal range (bio_2), accounting for $58.8 \%, 15.3 \%, 9 \%$, and $6 \%$, respectively (Table 1). These four variables are representative of all four major aspects of environmental variables (temperature, land factor, altitude, and precipitation) included in the model.

MaxEnt produces response curves to illustrate how each variable affects the prediction. The curves show how the logistic prediction changes as each variable are varied, keeping all other variables at their average sample value (Phillips et al. 2006). Altitude, by far, was the most important determinant in the model, with the response curve indicating positive correlation between the increase in altitude level and increase in probability of occurrence which started its significant value at around $1,000 \mathrm{~m}$ a.s.1 and reached its peak at about $2,100 \mathrm{~m}$ a.s.l before decreased gradually at higher altitude to a level below 0.5 (Figure 2.A). The second most important predictor was annual mean temperature, suggested high probability of occurrence in a narrow range of temperatures between 13 and $18^{\circ} \mathrm{C}$, then the probability dropped lower and even reach zero at temperature higher than $24^{\circ} \mathrm{C}$ (Figure 2.B). The next important variable was geology feature, represented with a code number for each category of geological feature. According to Figure 2.C, the highest probability of presence was on Qlv (code number 295) type of rocks which has been approximately existed since the Holocene epoch (1.26 ma) (Hudson 2013). The next notable geological feature was Qtp (code number 281) type of rocks, which has approximately been dated back to the Pleistocene epoch (2.6 ma) (Bhat et al. 2012). These types of rock are classified as volcanic rock which is often found in Java since this island contains numerous volcanoes. Therefore, since these types of geological feature are abundance in highland region in Java, both mountainous Selaginella is often found in these types of rock. The fourth important variable was precipitation of wettest month 
(bio_13), which represents the mean precipitation during wet season. Figure 2.D illustrates a high probability at precipitation above $600 \mathrm{~mm}$, and increasing along with higher precipitation rate.

\section{Model of geographical distribution under current climate condition}

The model of potential distribution of mountainous Selaginella under current climate condition is shown in Figure 3. The figure illustrates their wide distribution, with numerous patches of varying sizes and levels of suitability across mountainous areas in Java Island. According to our model, only about $5.07 \%\left(6,436 \mathrm{~km}^{2}\right)$ of the areas in Java Island is suitable for $S$. opaca and $S$. remotifolia habitat. The number consists of $4,266 \mathrm{~km}^{2}(3.35 \%), 1,751 \mathrm{~km}^{2}$ $(1.37 \%)$, and $417 \mathrm{~km}^{2}(0.32 \%)$ of low, medium, and high probability area respectively. The greatest concentration of suitable habitat is observed covering three mountains in Central Java Province, Indonesia, i.e. Mt. Sumbi, Mt. Sundoro, and Mt. Dieng. This area is expected to have the best climatic and environmental conditions to support the habitat of mountainous Selaginella. Another noticeable area with a wide medium probability is in Mt. Merapi. Mount Merapi is a volcanic mountain located in Central Java province and has several steep slopes with dense vegetation on its lower flanks.

There is a clear division of predicted distribution between the central region and both the western and eastern regions of Java, even though these sites have been recorded carefully with respectable number of locality points. Low probability area in western Java is dominant and distributed widely in small patches. Likewise, low probability area is also dominant in eastern part of Java but with larger patch. The pattern could be due to the difference of unique climatic features between these regions. Another explanation may relate to model sensitivity or data inaccuracies, for example, the scale of bioclimatic data which is larger than many small suitable bioclimatic spaces.

Table 1. Percentages of variables contribute to the final model in MaxEnt

\begin{tabular}{lc}
\hline Environmental variables & $\begin{array}{c}\text { Contribution } \\
(\%)\end{array}$ \\
\hline Altitude (Alt) & 53.1 \\
Annual Mean Temperature $\left({ }^{\circ} \mathrm{C} * 10\right)$ (bio_1) & 21.2 \\
Geology feature & 10 \\
Precipitation of Wettest Month (bio_13) & 5.6 \\
Mean Diurnal Range (Mean of monthly (max & 3.6 \\
temp - min temp)) (bio_2) & \\
Temperature Seasonality (standard deviation & 1.4 \\
*100) (bio_4) & 1.1 \\
Soil type & 1.1 \\
Isothermality (bio_3) & 1 \\
Annual Precipitation (bio_12) & 0.7 \\
Precipitation of Coldest Quarter (bio_19) & 0.6 \\
Precipitation of Warmest Quarter (bio_18) & 0.6 \\
Precipitation Seasonality (bio_15) & \\
\hline
\end{tabular}

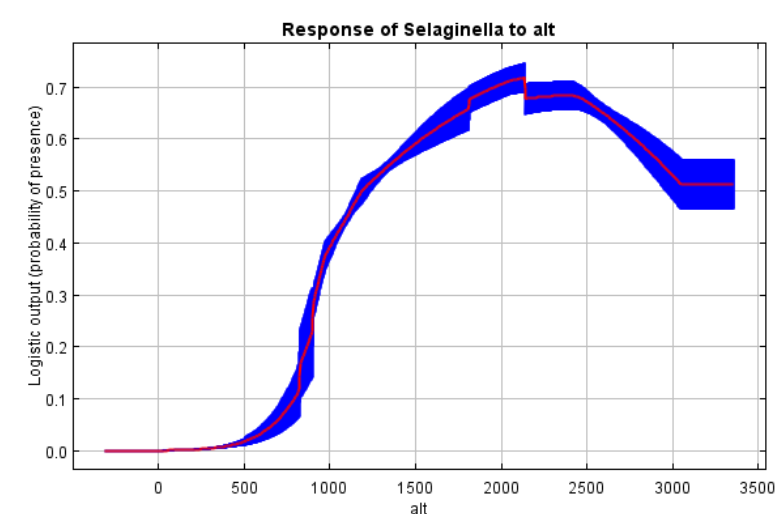

A

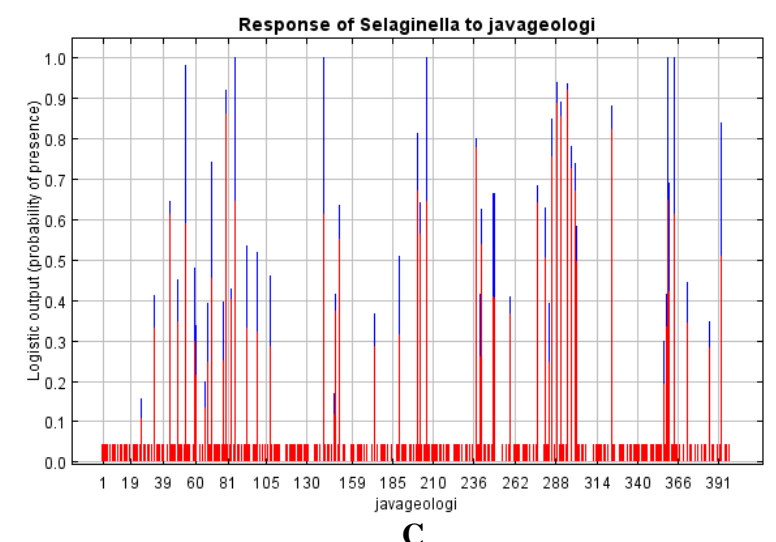

C

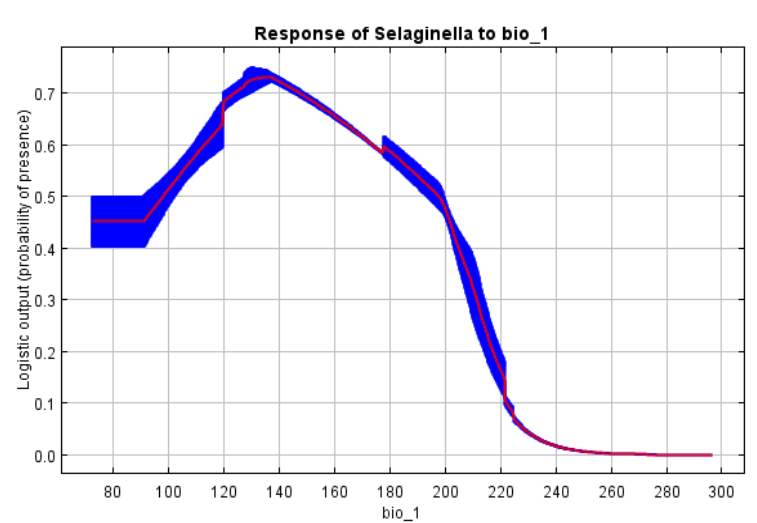

B

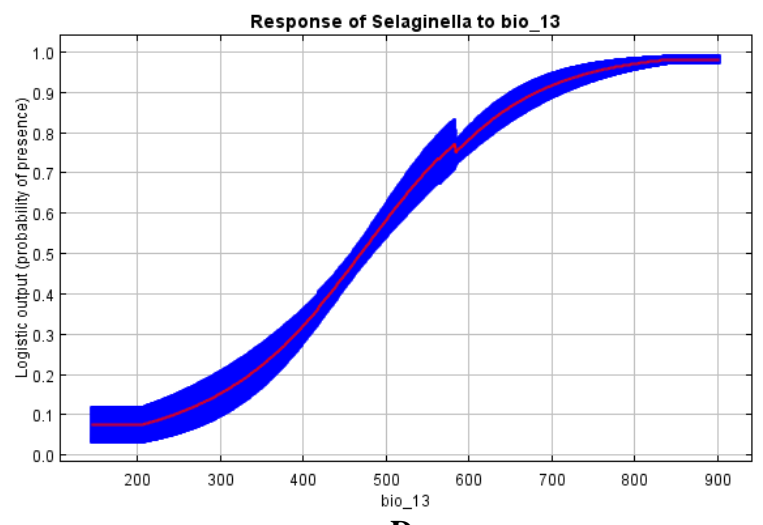

D

Figure 2. Response curves from MaxEnt to the most important variables for the species distribution model of $S$. opaca and $S$. remotifolia: A. Altitude; B. Annual mean temperature (in $\left.{ }^{\circ} \mathrm{C}^{*} 10\right)$; C. Geology feature; D. Precipitation of Wettest Month (in $\mathrm{mm} / \mathrm{month}$ ) 

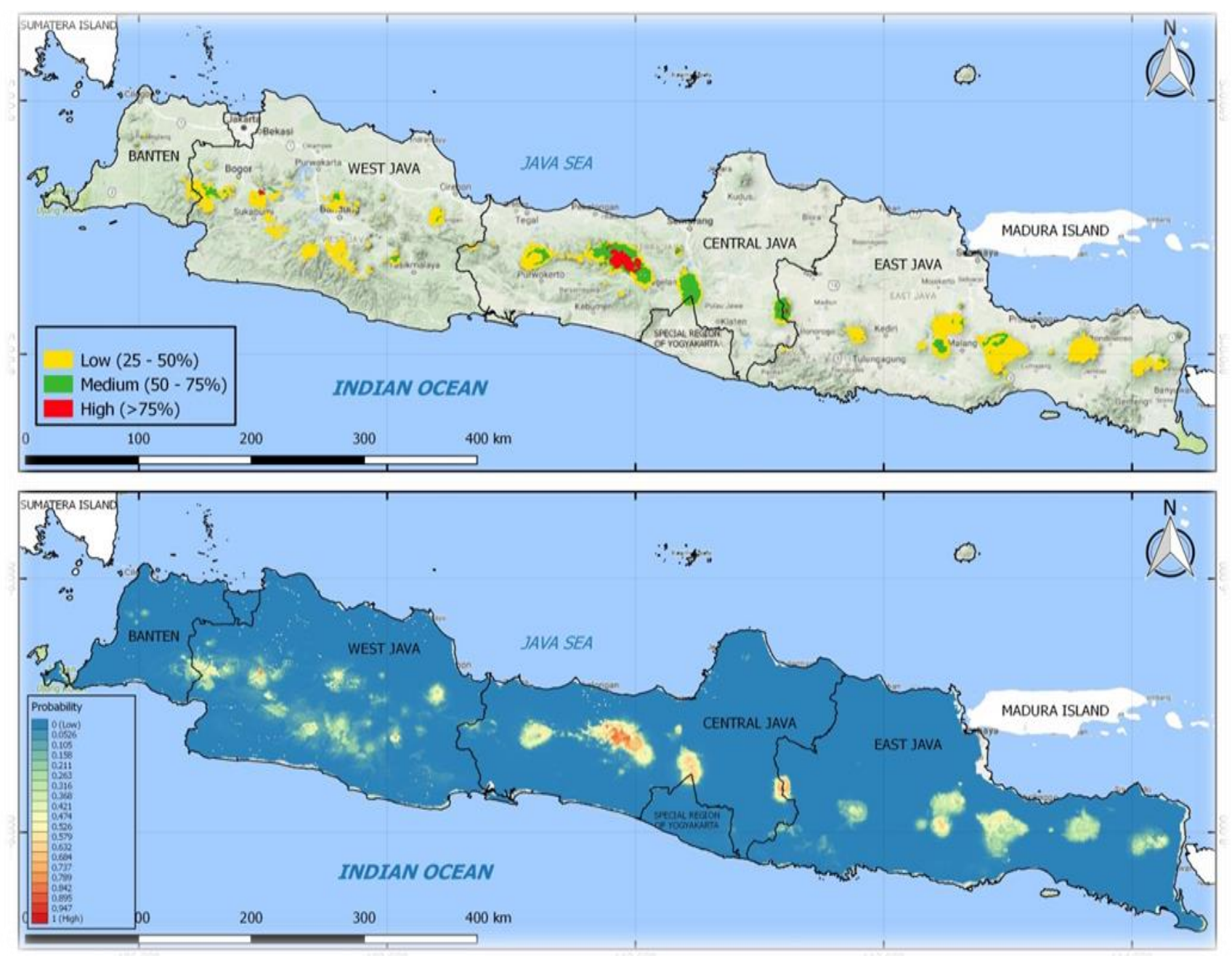

Figure 3. Predicted potential distribution of Selaginella opaca and S. remotifolia under current bioclimatic condition.

\section{Prediction of future geographical distribution}

Prediction of the potential impact of climate change on the distribution of $S$. opaca and $S$. remotifolia is shown in Figure 4 . The future modeled scenarios shows a significant decrease in predicted climatically suitable habitat for both species across all scenarios in the given periods of time (Figure 5). The area which has been predicted as mostly affected by climate change is the western part of Java. Model predicted that the suitable habitat in this area will decrease by $15-38 \%$ in all climate scenarios. In the RCP 2.6 scenario (lower emission by the end of century, but with significant increase in the first quarter of century) the highest suitability area will likely decrease by almost $40 \%$ in 2080, while the medium and low suitability area in this scenario will fall marginally.

Likewise, in RCP 4.5 and RCP 6.0 (GHG emission will increase dramatically but managed to be stabilized by the end of century), the downward trend of the high suitability area is predicted to be greater than the trend in RCP 2.6. Of the $417 \mathrm{~km}^{2}$ of high suitability area in the current condition, more than half $\left(287 \mathrm{~km}^{2}\right)$ will be lost by the end of 2080 under RCP 4.5 climate scenario, and about $295 \mathrm{~km}^{2}$ of that area will be lost under RCP 6.0 climate scenario by the same period of time. RCP 8.5 is predicted to have the most impact on the distribution of suitable habitat of $S$. opaca and $S$. remotifolia. Under this climate projection, both low and medium suitability areas will be gradually decreased while becoming centralized as the higher level of suitability areas are concentrated in the central part of Java. Furthermore, in this scenario, Java Island will only have 98 $\mathrm{km}^{2}$ left of high suitability area for both mountainous Selaginella in 2080.

The projected climate change also observed to affect the altitudinal distribution of mountainous Selaginella (Figure 6, Table 2). The average elevation of the distribution of mountainous Selaginella under three climate change pathways: RCP 6.0 (2050), RCP 2.6 (2080), and CP 6.0 (2080) are marginally lower than the average elevation under current climate condition. In contrast, higher average elevation of the distribution is shown under RCP 2.6 (2030) climate pathway. Based on the independent t-test between the altitude means of potential distribution range under current climate conditions and that of future climate conditions, all of these changes are statistically significant ( $p=0.01$ ). On the other hand, other climate change scenarios show a decrease in average elevation of the distribution. However, none of these changes were statistically significant. 


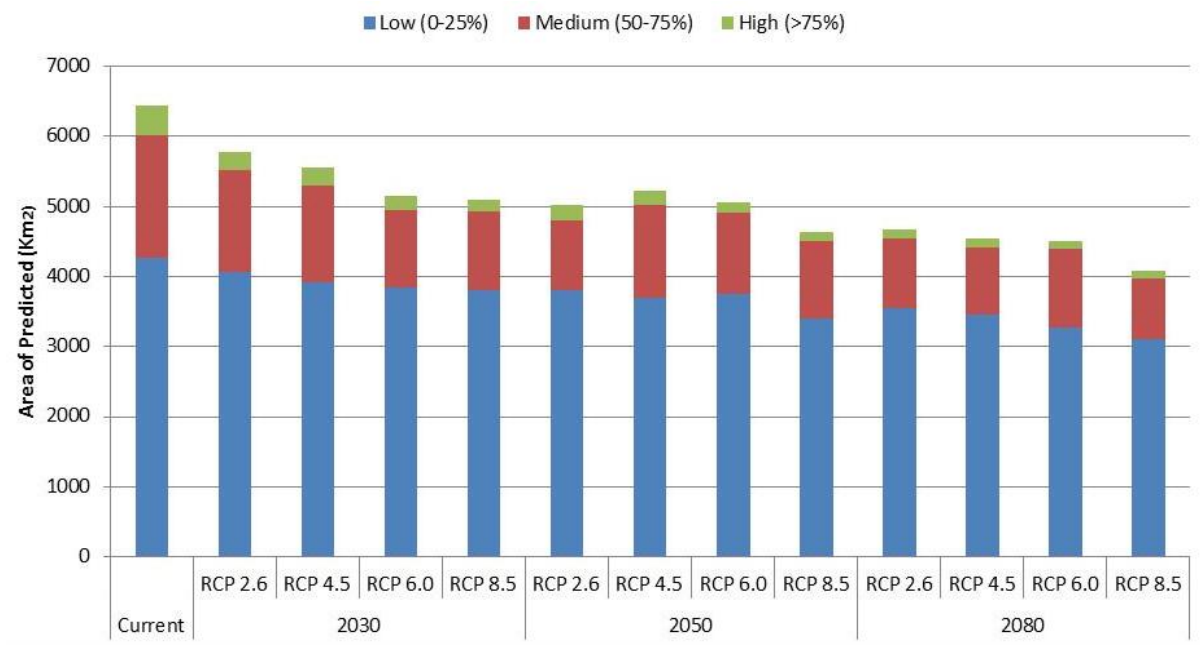

Figure 4. Estimated areas of the predicted distribution of Selaginella opaca and S. remotifolia habitat under future bioclimatic conditions
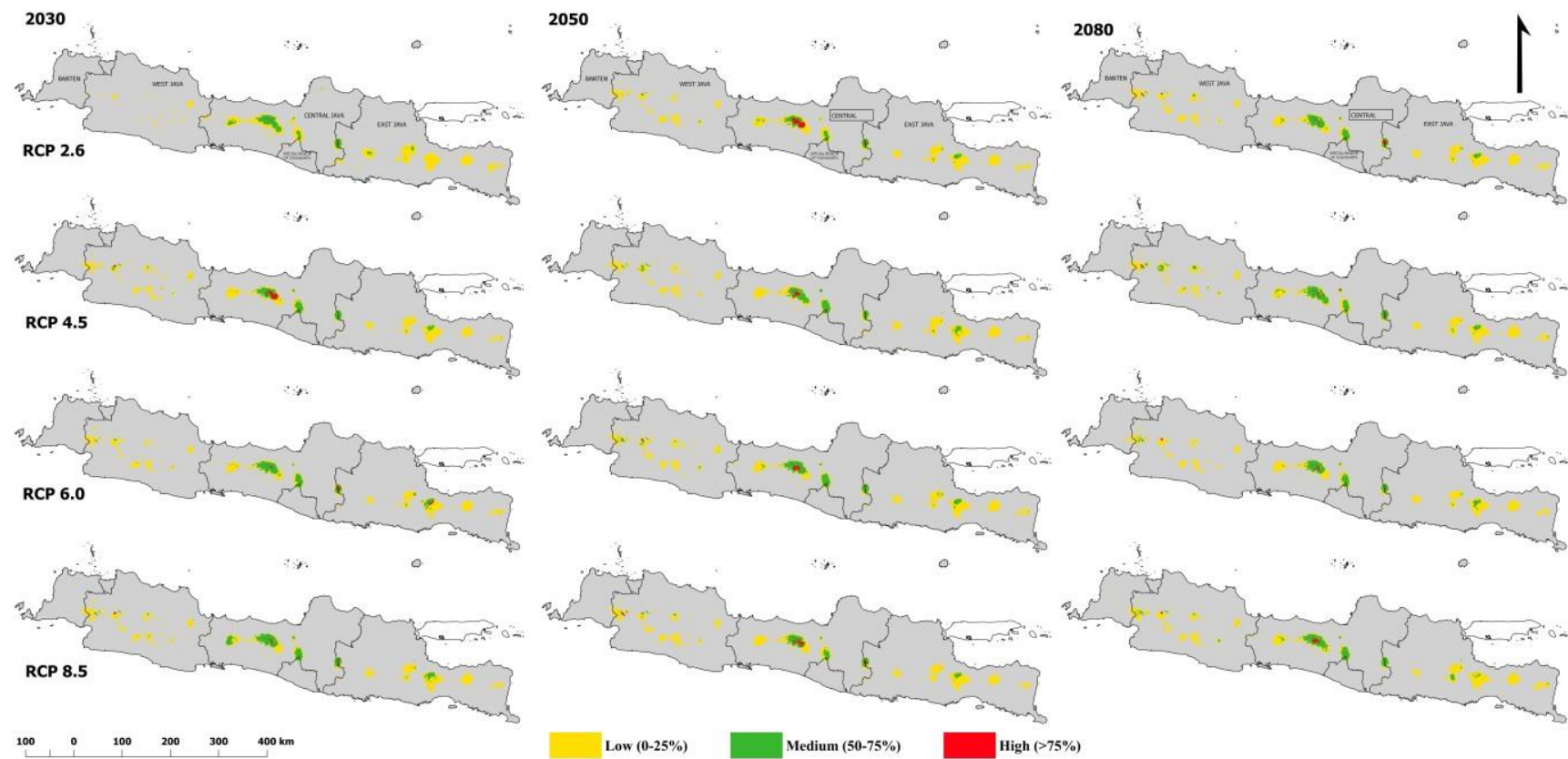

Figure 5. Prediction of future geographical distribution of Selaginella opaca and S. remotifolia under four climate change scenarios.

Table 2. Independent T-test between average elevation of current and future distributed predictions

\begin{tabular}{lllll}
\hline Climate scenarios & Year & Mean & SD & P-value \\
\hline Current condition & - & 1668.66 & 585.21 & - \\
RCP 2.6 & 2030 & 1745.5 & 544.06 & $1.82 \mathrm{E}-07$ \\
RCP 4.5 & 2030 & 1666.06 & 585.45 & 0.85 \\
RCP 6.0 & 2030 & 1652.22 & 587.75 & 0.24 \\
RCP 8.5 & 2030 & 1651.17 & 586.21 & 0.21 \\
RCP 2.6 & 2050 & 1643.26 & 585.21 & 0.06 \\
RCP 4.5 & 2050 & 1667.09 & 575.59 & 0.9 \\
RCP 6.0 & 2050 & 1624.48 & 570.53 & 0.001 \\
RCP 8.5 & 2050 & 1644.24 & 584.13 & 0.07 \\
RCP 2.6 & 2080 & 1602.35 & 574.06 & 0.0001 \\
RCP 4.5 & 2080 & 1639.12 & 578.25 & 0.03 \\
RCP 6.0 & 2080 & 1626.28 & 556.87 & 0.001 \\
RCP 8.5 & 2080 & 1658.06 & 586.7 & 0.44 \\
\hline
\end{tabular}

\section{Discussion}

Java as the most densely populated island in Indonesia, home to about $57 \%$ of Indonesia's population, will likely suffer more from the worsening human-induced climate change. The fact that this island has a high level of biodiversity (Myers et al. 2000), urges many efforts to study the response of biodiversity to the impacts of climate change. Projection of climate change in Java Island by Measey (2010) predicted a rise in the mean temperature by 0.40 to $0.41{ }^{\circ} \mathrm{C}$ in 2020 , and has been predicted to increase by 2.0 to $2.5^{\circ} \mathrm{C}$ at the end of $21^{\text {st }}$ century by Gosling et al. (2011). This study illustrates the first attempt to model the distribution of mountainous Selaginella under current and future climate conditions. Since the change in climate condition has already impacted Selaginella's habitat in the past time in several places (e.g. Boettger 2009; Cao et al. 
2010; Bezrukova et al. 2012), it will likely affect the distribution of this genera under future climate condition in Java Island as well. Therefore, this study provides a model that could predict the impact of climate change on mountainous Selaginella's distribution driven by several representative greenhouse gas concentration pathways.
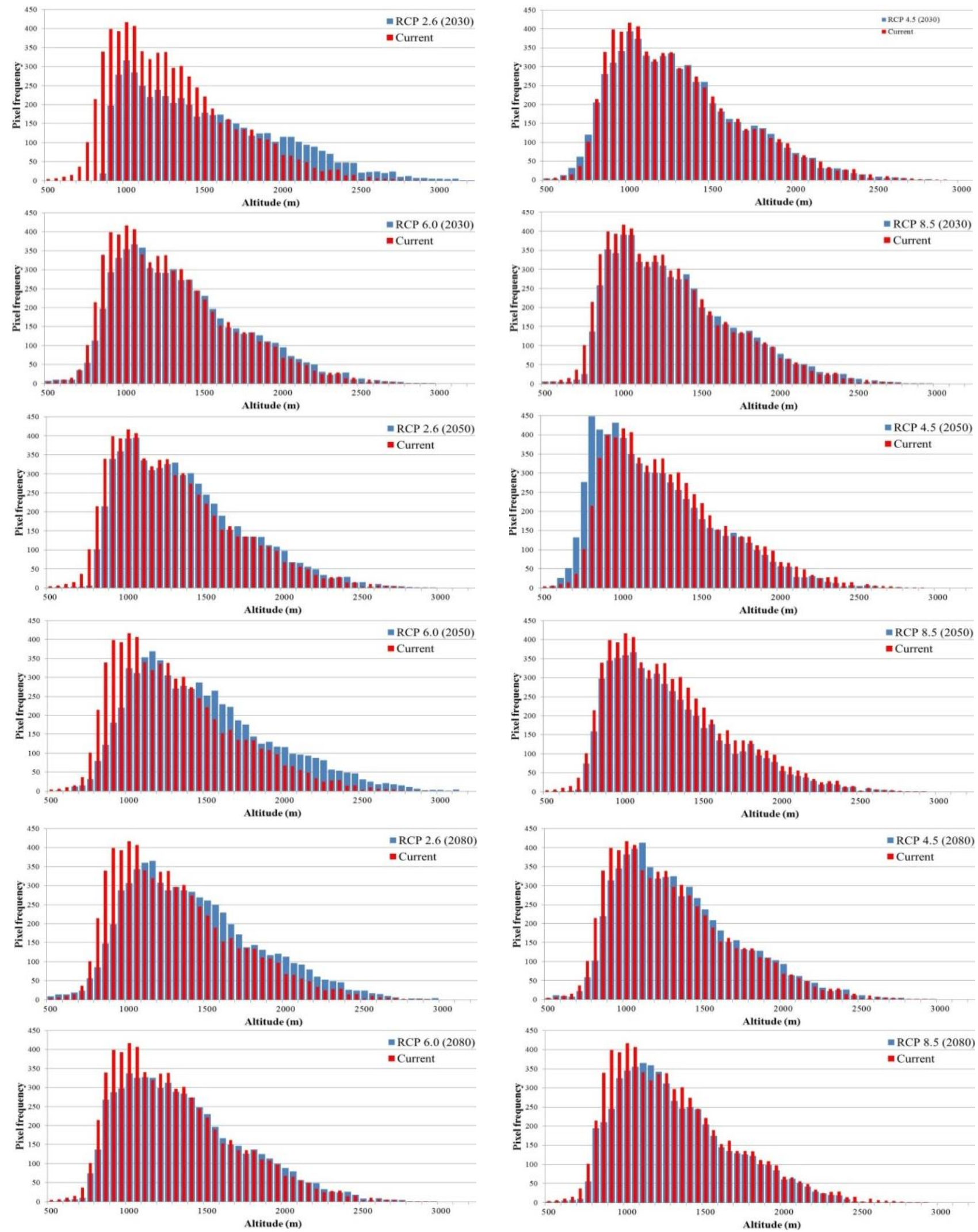

Figure 6. Change in average altitudinal distribution of Selaginella opaca and S. remotifolia under four future climate scenarios 
Our study represents a robust result of a modeling attempt driven by carefully selected locality data and bioclimatic variables. Despite the fundamental problem when using AUC (Area Under the Curve) to validate species distribution modeling, we retrieved the AUC value of 0.957 , indicating that the prediction in this study was far better than random prediction and that the selected variables have described the distribution of mountainous Selaginella acceptably. Furthermore, additional evaluation of the model was conducted using True Skill Statistic (TSS) to give further confidence in the output of this model. The TSS value of 0.81 gives the impression that the model built in this study has a very good degree of agreement (Li and Guo 2013). Regarding the AUC, its value is highly correlated to prevalence of the locality points and the size of the study area (Lobo et al. 2008). Consequently, this would generate some sort of bias or misunderstanding, for example, if one uses a small study region or if the locality points are localized in small area and the prevalence is small, one would get a high AUC value. Moreover, AUC, just like Kappa, is reliable only if we use PA (Presence-Absence) model due to the fact that both AUC and Kappa are weighting omission and commission errors equally. Thus, in case of this study where presence-only data was used, AUC and Kappa are not necessarily reliable.According to Setyawan et al. 2015, Selaginella is a herbaceous plant that will likely grow in the moist or rather wet region. Thus, since Java Island is a tropical island, elevation, which has a strong relationship with the level of humidity, plays another important role in the growth and the distribution of mountainous Selaginella. Then, temperature, as a regulator of evapotranspiration level, will become highly important factor as well in order to maintain the level of humidity in the region. Our study that illustrates the importance of altitude, temperature, and precipitation (see results) is in line with the knowledge about the habitat needs of mountainous Selaginella. Geological feature, on the other hand, may not represents the preference growth region of mountainous Selaginella, but rather to represents the geological feature in the highland region of Java. In this regard, the result of our study shows only the geological feature that predominantly will be found in the volcanoes region. The fact that Java island is part of circum-Pacific belt region (USGS 2012) adds confidence to the former allegation that this result represents only the dominant feature in the mountainous region of Java, rather than the actual preferred geological feature of the growth and distribution of $S$. opaca and $S$. remotifolia.

Despite the limitation to inspect the current distribution predicted by this study across Java Island, there are several conformities with the distribution of $S$. opaca and $S$. remotifolia found by Setyawan et al. (2015) and Setyawan (2016) in Mt. Merapi and in the Dieng plateau, respectively. These areas, by our model, represent a wide area of medium to high level of habitat suitability. However, the model might be slightly underestimating the potential distribution in the western region of Java since several mountainous areas in this region have the same altitudinal and geological feature with the one in the central and eastern regions. Although the TSS value suggests a very good degree of agreement of this model, further exploration is needed to confirm whether there are several factors that distinguish the western region from the rest of region or whether mainly because of the limitation of the model.

Based on our model, the negative impacts of future climate condition is illustrated by major decrease in the level of habitat suitability and the total area of habitat distribution. The total area of habitat is expected to decrease by $1.8 \%$ to $11.4 \%$ under all climate change trajectories. The most favorable climate scenario is RCP 2.6 (in all periods of time) which predicts no more than 5\% of suitable habitat losses. Lower altitude regions under 900 $\mathrm{m}$ a.s.l across the island are predicted by this scenario to lost its capability to support the sustainability of mountainous Selaginella. Likewise, the worst scenario in this study (RCP 8.5) is predicted not only the lost capability of lower altitude but also lowering the level of habitat suitability in the higher region. The highest level of habitat suitability which concentrated in the region between Mt. Sumbing, Mt. Sundoro, and Mt. Dieng is likely to decrease by almost $60 \%$ (Figure 4 ).

Mean temperature in Indonesia under future climate conditions is projected to increase by 0.72 to $3.92{ }^{\circ} \mathrm{C}$ (Crus et al. 2007) depending on different scenarios. Theoretically, since climate in Indonesia is strongly influenced by El Nino Southern Oscillation (ENSO) events, rising in temperature may lead to an excessive drought which in the end will drop the humidity level. Consequently, the increasing level of evaporation in some areas of Indonesia (induced by high-level temperature) would intensify the earth's water cycle, resulting in higher risk of storm and flooding in another Indonesian area during La Nina events. However, annual precipitation in Indonesia is projected to have an opposite path of change. Boer and Faqih (2004) stated that there is significant spatial variability in annual precipitation across all of Indonesia over the last century. They stated that there has been a significant decline in annual rainfall of southern regions of Indonesia (e.g. Java Island, Lampung, South Sumatera, South Sulawesi, and Nusa Tenggara) and an increase of precipitation level in the northern regions of Indonesia (e.g., most of Kalimantan, North Sulawesi, etc). Furthermore, Cruz et al. (2007) gave an estimation number of two percent of the declining precipitation and up to four percent of the increasing level of precipitation by the end of the century.

Since Java Island has been predicted to have a higher level of temperature and lower level of annual precipitation, the average elevation of the suitable habitat for mountainous Selaginella may change. Despite the statistically insignificant value (with the exception in RCP 2.6 in 2030), the average altitude of suitable habitat will mostly be shifted to a higher elevation. Hypothetically, the shift may be triggered by the ability of the higher altitude area to maintain the high humidity level in spite of the anomaly of temperature and precipitation level in Java Island. In contrast, our model also predicted a lower average of altitudinal distribution under several climate trajectories. It is unclear to explain what factors may induce 
a decrease in altitudinal range under these climate trajectories. The most possible approach is to monitor the impact of past climate change on the distribution of mountainous Selaginella. Nevertheless, this approach is impossible to be conducted due to unavailability of historical data on the distribution of mountainous Selaginella.

The model built in this study, certainly, has some limitations. Single-species approach via bioclimatic modeling and the absence of more detailed ecological and physiological data are some of the major limitations in the assessment of climate change impact (Hampe 2004; Morin and Thriller 2009; Sinclair et al. 2010; Ellis 2011). Other limitations are related to the spatial resolution of bioclimatic variables. The 30 arcs second resolution used in this study may greater than the range size distribution of mountainous Selaginella. However, since new climate models are currently developed while the existing are refined, future research may have the opportunity to reanalyze this existing data under finer temporal and spatial resolution. Further precise modeling of the distribution trends of mountainous Selaginella in the future, shall incorporate future model of land use/land cover change and biotic interactions between species in the regional ecosystems. Moreover, sophisticated models to be developed in the future shall include microclimatic variables and landscape heterogeneity of Java Island.

\section{REFERENCES}

Allouche O, Tsoar A, Kadmon R. 2006. Assessing the accuracy of species distribution models: prevalence, kappa and the true skill statistic (TSS). J Appl Ecol 43 (6): 223-1232.

Anderson RP, Lew D, Peterson AT. 2003. Evaluating predictive models of species' distributions: criteria for selecting optimal models. Ecol Model 162: 211-232.

Anderson RP, Raza A. 2010. The effect of the extent of the study region on GIS models of species geographic distributions and estimates of niche evolution: preliminary tests with montane rodents (genus Nephelomys) in Venezuela. J Biogeo 37: 1378-1393.

Bahn V, Brian JM. 2006. Testing the predictive performance of distribution models. Synth Ecol 43 (6): 1223-1232.

Baldwin, Roger A. 2009. Use of maximum entropy modeling in wildlife research. Entropy 11 (4): 854-866.

Banks JA. 2009. Selaginella and 400 Million Years of Separation. Ann Rev Plant Biol 60: 223-238.

Berry PM. 2002. Modelling potential impacts of climate change on the bioclimatic envelope of species in Britain and Ireland. Glob Ecol Biogeo 11: 453-462.

Bezrukova EV, Anderson, Vinkovskaya, Kharinsky, Kulagina NV. 2012. Paleoenvironment: The stone age. Archae Ethno Anthrop Eurasia 40 (3) (2012): 2-11.

Bhat GM, Craig J, Thurow J, Thusu B. 2012. Geology and Hydrocarbon Potential of Neoproteozoic-Cambrian Basins in Asia. The Geological Society. London.

Boettger T, Hiller A, Frank W, Junge, Mania D, Kremenetski K. 2009 Late Glacial/Early Holocene environmental changes in Thuringia, Germany: Stable isotope record and vegetation history. Quarter Int 203: 105-112.

Botkin DB, Saxe H, Miguel B, et al. 2007. Forecasting the Effects of Global Warming on Biodiversity. Biosci 57 (3): 227-238.

Box EO. 1981. Predicting physiognomic vegetation types with climate variables. Veg 45: 127-139.

Cao X, Xu Q, Jing Z, Tang J, Li Y, Tian F. 2010. Holocene climate change and human impacts implied from the pollen records in Anyang, central China. Quater Int 227: 13-26.
Chan LM, Brown JL, Yoder AD. 2011. Integrating statistical genetic and geospatial methods brings new power to phylogeography. Mol Phy Evol 59: 523-537.

Clarke L, Edmonds J, Jacoby H, Pitcher H, Reilly J, Richels R. 2007. Scenarios of Greenhouse Gas Emissions and Atmospheric Concentrations. Sub-report 2.1A of Synthesis and Assessment Product 2.1 by the U.S. Climate Change Science Program and the Subcommittee on Global Change Research. Department of Energy, Office of Biological \& Environmental Research, Washington DC.

Collins WJ, Bellouin N, Doutriaux-Boucher M, Gedney N, Halloran P, et al. 2011. Development and evaluation of an Earth-System modelHadGEM2. Geosci Model Dev Discuss 4: 997-1062.

Cruz RV, Harasawa H, Lal M, et al. 2007: Asia. Climate Change 2007: Impacts, Adaptation and Vulnerability. Contribution of Working Group II to the Fourth Assessment Report of the Intergovernmental Panel on Climate Change. In: Parry ML, Canziani OF, Palutikof JP. van der Linden, Hanson CE (eds). Cambridge University Press, Cambridge.

Duan RY, Xiao-Quan K, Min-Yi H, Sara V, Xiang J. 2016. The potential effects of climate change on amphibian distribution, range fragmentation and turnover in China. PeerJ 4: 165-174.

Dubuis A, Rossier L, Pottier J, Pellissier L, Pascal V, Guisan A. 2013. Predicting current and future spatial community patterns of plant functional traits. Ecography 36: 001-011.

Ebihara A, Fraser-Jenkins CR, Parris BS, Zhang XC. 2012. Rare and threatened pteridophytes of Asia 1. An enumeration of narrowly distributed taxa. Bull Natl Mus Nat Sci 38 (3): 93-119.

Elith J, Graham CH, Anderson P, Dudik M, Ferrier S, et al. 2006. Novel methods improve prediction of species distributions from occurrence data. Ecograph 29: 129-151.

Elith J, Kearney M, Phillips SJ. 2010. The art of modelling range-shifting species. Methods Ecol Evol 1: 330-342.

Elith J, Leathwick JR. 2009. Species Distribution Models: Ecological Explanation and Prediction Across Space and Time. Annu Rev Ecol Evol Syst 40:677-97.

Ellis CJ (2011) Predicting the biodiversity response to climate change: challenges and advances. Syst Biodivers 9: 307-317.

Ellis CJ. 2011. Predicting the biodiversity response to climate change: challenges and advances. Syst Biodivers 9: 307-317.

Engler R, Guisan A. 2009. MigClim: Predicting plant distribution and dispersal in a changing climate. Divers Distrib 15 (4): 590-601.

Ersts PJ. 2012. Geographic Distance Matrix Generator (version 1.2.3). American Museum of Natural History. Center for Biodiversity and Conservation. www.biodiversityinformatics.amnh.org/open source/gdmg.

Fitzpatrick MC, Weltzin JF, Sanders NJ, Dunn RR. 2007. The biogeography of prediction error: why does the introduced range of the fire ant over-predict its native range. Glob Ecol Biogeo 16 (1): 2433 .

Forman TT. 1964. Growth under controlled conditions to explain the hierarchical distributions of a moss, Tetraphis pellucida. Ecol Monogr 34: 1-25.

Fourcade Y, Engler JO, Rodder D, Secondi J. 2014. Mapping species distributions with MAXENT using a geographically biased sample of presence data: A performance assessment of methods for correcting sampling bias. PLoS ONE 9 (5): e97122. DOI: 10.1371/journal.pone.0097122.

Fox J. 2010. Polycor: polychoric and polyserial correlations, R package version 0.7-8. www.CRAN.R-project.org/package=polycor. [12 June 2017].

Fujino J, Nair R, Kainuma M, Masui T, Matsuoka Y. 2006. Multi-gas mitigation analysis on stabilization scenarios using AIM global model. En J Mitig Climat 3: 343-354.

Garavito TN, Golicher D, Oldfield S. 2015. The Relative Impact of Climate Change on the Extinction Risk of Tree Species in the Montane Tropical Andes. PLoS ONE 10 (7): e0131388. DOI: 10.1371/journal.pone.0131388.

Gosling SN, Dunn R, Carrol F, et al. 2011. Climate: Observations, projections and impacts: Indonesia. Met Office Publisher. Devon.

Graham CH, Elith J, Hijmands R, Peterson AT, Loiselle B. 2009. The influence of spatial errors in species occurrence data used in distribution models. J App Ecol 45 (1): 239-247.

Hampe A (2004) Bioclimate envelope models: what they detect and what they hide. Global Ecol Biogeogr 13: 469-476. 
Hariyati JH, Arisoesilaningsih E, Hakim L. 2013. Seedling growth of some native trees in Ranu Pani- Ranu Regulo restoration area, Bromo Tengger Semeru National Park. J Biodiv Environ Sci 3 (6): 47-55.

Harrison D, Prabhu G, Grieve R, et al. 2013. Risk adjustment in neurocritical care (rain)-prospective validation of risk prediction models for adult patients with acute traumatic brain injury to use to evaluate the optimum location and comparative costs of neurocritical care: a cohort study. Health Technol Assess 17 (23): 313-350.

Hudson MR. 2013. New Perspectives on Rio Grande Rift Basins: From Tectonics to Groundwater. The Geological Society of America. Colorado.

Intergovernmental Panel on Climate Change [IPCC]. 2007. Climate change 2007: the physical science basis, summary for policy makers. www.ipcc.ch. [13 June 2013].

Johnston KM, Freund KA, Schmitz OJ. 2012. Projected range shifting by montane mammals under climate change: implications for Cascadias National Parks. Ecosphere 3 (11): 97-116.

Jorim RY, Korape S, Legu W, et al. 2012. An ethnobotanical survey of medicinal plants used in the eastern highlands of Papua New Guinea. J Ethnobiol Ethnomed. DOI: 10.1186/1746-4269-8-47

Korall P, Kenrick P. 2004. The phylogenetic history of Selaginellaceae based on DNA sequences from the plastid and nucleus: extreme substitution rates and rate heterogeneity. Mol Phylo Evol 31: 852-864.

Kou X, Li Q, Liu S. 2011. Quantifying Species' Range Shifts in Relation to Climate Change: A Case Study of Abies spp. in China. PLoS ONE 6 (8): e23115. DOI: 10.1371/journal.pone.0023115.

Kumar S, Stohlgren TJ. 2009. Maxent modeling for predicting suitable habitat for threatened and endangered tree Canacomyrica monticola in New Caledonia. J Ecol Nat Environ 1 (4): 94-98.

Linda JB, Lesley H. 2002. Potential changes in the distributions of latitudinally restricted Australian butterfly species in response to climate change. Glob Ch Bio 8 (10): 954-971.

Lobo JM, Jimenez-Valverde A, Real R. 2008. AUC: a misleading measure of the performance of predictive distribution models. Global Ecol Biogeogr 17 (2): 145-151.

Lobo JM, Jiménez-Valverde A, Real R. 2008. AUC: a misleading measure of the performance of predictive distribution models. Glob Ecol Biogeo 17: 145-151.

Mariah Measey. 2010. Indonesia: A vulnerable country in the face of climate change. Glob Major J 1 (1): 31-45.

Merow C, Smith MJ, Silander JA. 2013. A practical guide to MaxEnt for modeling species' distributions: what it does, and why inputs and settings matter. Ecograph 36 (10): 1058-1069.

Montgomery R, Roloff GJ, Hoef JMV. 2011. Implications of ignoring telemetry error on inference in wildlife resource use models.J Wild Manag 75: 702-708.

Montgomery R, Roloff GJ, Hoef M. 2011. Implications of ignoring telemetry error on inference in wildlife resource use models. J Wildl Manag 75: 702-708.

Morin X, Thuiller W (2009) Comparing niche- and process-based models to reduce prediction uncertainty in species range shifts under climate change. Ecol Lett 90: 1301-1313.

Myers, Norman, Russell MA, Cristina GM, et al. 2000. Biodiversity hotspots for conservation priorities. Nat 403 (6772): 853-858

Pearson RG, Dawson TP. 2003. Predicting the impacts of climate change on the distribution of species: are bioclimate envelope models useful? Glob Ecol Biogeogr 12: 361-371

Pearson RG, Raxworthy C, Nakamura M, Peterson AT. 2007. Predicting species distributions from small numbers of occurrence records: a test case using cryptic geckos in Madagascar. J Biogeo 34: 102-117.

Phillips SJ, Anderson RP, Schapire RE. 2013. Maximum entropy modeling of species geographic distribution. Ecol Model 19: 231-259.

Phillips SJ, Dudık M, Elith J, Graham CH, Lehmann A, et al. 2009. Sample selection bias and presence-only distribution models: implications for background and pseudo-absence data. Ecol Appl 19: 181-197.

Porfirio LL, Harris RM, Lefroy EC, Hugh S, Gould SF, Lee G, et al. (2014) Improving the use of species distribution models in conservation planning and management under climate change. PLoS ONE 9 (11): e113749. DOI: 10.1371/journal.pone.0113749.

Qian JH, Robertson JW, Moron V. 2010. Interactions among ENSO, the Monsoon, and Diurnal Cycle in Rainfall Variability over Java, Indonesia. J Atm Sci 67: 3509-3524.

Ramirez J, Jarvis A. 2008. High resolution statistically downscaled future climate surfaces. International Center for Tropical Agriculture (CIAT); CGIAR Research Program on Climate Change, Agriculture and Food Security (CCAFS) Cali, Colombia. www.ccafsclimate.org/statistical_downscaling_delta [1 June 2017].

Randin CF, Dirnbock T, Dullinger S, et al. 2006. Are niche-based species distribution models transferable in space?. J Biogeo 33: 1689-1703.

Randin CF, Engler R, Normand S, et al. 2008. Climate change and plant distribution: local models predict high-elevation persistence. Glob $\mathrm{Ch}$ Biol 15 (6): 1557-1569.

Riahi K, Rao S. Krey V. et al. 2011. RCP 8.5-A scenario of comparatively high greenhouse gas emissions. Climatic Change 109 (33): 364-379.

Rondini C, Wilson KA, Boitani L, et al. 2006. Tradeoffs of different types of species occurrence data for use in systematic conservation planning. Ecol Lett 9: 1136-1145.

Rondinini C, Wilson KA, Boitani L, Grantham H, Possingham HP. 2006. Tradeoffs of different types of species occurrence data for use in systematic conservation planning. Ecol Lett 9 (10): 1136-1145.

Rupa P, Bhavani NL. 2014. Diversity, conservation status and medicinal importance of Selaginella spp. In: Madhav V, Murthy N (eds.). Recent Trends in Plant Sciences. National Seminar on Recent Trends in Plant Science. Satavahana University, Telangana. 22-23 August 2014.

Schulz C, Homberg J, Stützel T. 2013. Taxonomic revision of Selaginella Subg. Ericetorum. Sys Bot 38 (1): 5-14.

Schulz C, Little DP, Stevenson DW, Bauer D, Moloney C, Stützel T. 2010. An overview of the morphology, anatomy, and life cycle of a new model species: The lycophyte Selaginella apoda (L.) Spring. Int J Plant Sci 171 (7): 693-712.

Setyawan AD, Darusman LK. 2008. Review: biflavonoid compounds of Selaginella Pal. Beauv. and its benefit. Biodiv 9 (1): 64-81.

Setyawan AD, Sugiyarto, Susilowati A, Widodo. 2015. Diversity and distribution of Selaginella in the province of Yogyakarta Special Region. Pros Sem Nas Masy Biodiv Indon 1 (5): 987-992.

Setyawan AD. 2009. Traditionally utilization of Selaginella; field research and literature review. Nusantara Biosci 1: 146-158.

Setyawan AD. 2011. Review: Recent status of Selaginella (Selaginellaceae) research in Nusantara. Biodiversitas 12 (2): 112124.

Shrestha UB, Bawa KS. 2014. Impact of climate change on potential distribution of Chinese caterpillar fungus (Ophiocordyceps sinensis) in Nepal Himalaya. PLoS ONE 9 (9): e106405. DOI: 10.1371/journal.pone.0106405.

Sinclair SJ, White MD, Newell GR. 2010. How useful are species distribution models for managing biodiversity under future climates? Ecol Soc 15: 8-16.

Singh SK, Dubey NK. Srivastava GK. 2016. The microspore morphology of some species of Selaginella (Selaginellaceae) from India. Palynol 40 (2): 216-229

Singh SK, Yadav BB, Srivastava M, Shukla PK, Srivastava GK. 2014. Comparative morphological studies on spikes of Indian Selaginella Beauv. Plant Syst Evol 300:1235-1245.

Summers DM, Bryan BA, Crossman ND, Meyer WS. 2012. Species vulnerability to climate change: impacts on spatial conservation priorities and species representation. Glob Change Biol 18 (7): 23352348

Summers DM, Bryan BA, Crossman ND, Meyer WS. 2012. Species vulnerability to climate change: impacts on spatial conservation priorities and species representation. Glob Change Biol 18 (7): 23352348.

Thomas R, Karl, Kevin E, Trenberth. 2003. Modern global climate change. Science 302: 1719-1723.

Thuiller W, Albert C, Araujo MB, et al. 2008. Predicting global change impacts on plant species distributions: future challenges. Percept Plant Ecol Evol Sys 9: 137-152.

van Vuuren D, den Elzen M, Lucas P, Eickhout B, Strengers B, et al. 2007. Stabilizing greenhouse gas concentrations at low levels: an assessment of reduction strategies and costs. Climat Chang 81: 119159.

Warren DL, Seifert SN. 2011. Ecological niche modeling in MAXENT: the importance of model complexity and the performance of model selection criteria. Ecol Appl 21: 335-342.

Weststrand S, Korall P. 2016. A subgeneric classification of Selaginella (Selaginellaceae). Am J Bot 103 (12): 2160 -2169.

Wijaya A. 2014. Diversity and distribution of Selaginella spp. In Indonesia from 1998 to 2014. El-Hayah 5 (1): 31-42.

Zamora P. 2012. Strobilar Organization in Philippine Species of Selaginella. J Pure Appl Sci 4 (2): 223-238. 
